\title{
CONDIÇÕES AMBIENTAIS DE ALGUMAS PROPRIEDADES AGRÍCOLAS DE SANTA FÉ DO SUL - SP E REGIÃO.
}

Reinaldo da Silva Tosti ${ }^{1}$

Sérgio Luis de Carvalho ${ }^{2}$

Elizete Aparecida Checon Freitas Lima ${ }^{3}$

\begin{abstract}
RESUMO
Este trabalho teve como objetivo avaliar as condições ambientais de algumas propriedades rurais de Santa Fé do Sul - SP e região, investigando a maneira com que os problemas ambientais são percebidos pelos produtores rurais. Foi elaborado um questionário, e a partir dele foram realizadas 45 entrevistas, com questões que detectaram a existência de degradação ambiental e a necessidade de um maior investimento na educação ambiental no meio rural para o município de Santa Fé do Sul e região. Para realizar a avaliação das condições encontradas nas propriedades do município, foi formulado um questionário, com cerca de 26 questões, contendo alternativas com respostas variadas, enfocando os principais problemas causadores de degradação ambiental atualmente na região em estudo. Foram abordadas no questionário questões ambientais preocupantes do ponto de vista agropecuário, entre as quais estão os problemas de contaminação de cursos d'água, a existência de matas ciliares, locais de lançamento de esgoto, além da identificação das fontes de água existentes nas propriedades. O trabalho constatou problemas nas temáticas abordadas, como por exemplo, a carência ou não existência de matas ciliares, nas fontes de água das propriedades analisadas, sendo portanto necessária a aplicação de programas de educação ambiental, a fim de formar pessoas mais conscientes, gerando assim melhorias para si mesmas e para o local onde vivem.
\end{abstract}

PALAVRAS-CHAVE: Educação Ambiental. Meio Ambiente. Sustentabilidade

1. Graduando em Agronomia, Unesp, Campus de Ilha Solteira. reinaldotosti@gmail.com

2. Prof. Adjunto, Doutor em Ecologia, Depto. de Biologia e Zootecnia da Unesp, Campus de Ilha Solteira. sergicar@bio.feis.br

3. Profa. Dra. Depto. de Biologia e Zootecnia da Unesp, Campus de Ilha Solteira. eacfl@bio.feis.unesp.br 


\title{
ENVIRONMENTAL CONDITIONS OF SOME PROPRIETIES OF SANTA FE DO SUL - SP AND REGION.
}

\begin{abstract}
This study aimed to assess the environmental conditions of some rural properties in Santa Fé do Sul - SP and region, assessing the way in which environmental problems are perceived by farmers. A questionnaire was developed, and from it 45 interviews were conducted with issues that detected the existence of environmental degradation and the need for greater investment in environmental education in rural areas to the city of Santa Fe and South region. In order to evaluate the conditions found in the properties of the municipality, was formulated a questionnaire with about 26 questions containing alternatives with varying responses, focusing on the main problems causing environmental degradation in the region currently under study. Were addressed questionnaire which concern environmental issues from the point of view of agriculture, among which are the problems of contamination of streams, riparian forests existing, launch sites sewer, beyond the identification of existing sources of water in the properties. The work found problems in the topics addressed, such as the lack or absence of riparian forests in water sources of the analyzed properties, making it necessary to apply environmental education programs in order to form people more aware generating improvements to themselves and to the local where they live.
\end{abstract}

KEYWORDS: Environmental Education. Environment. Sustainability.

\section{CONDICIONES AMBIENTALES DE ALGUNOS PROPIEDADES DE SANTA FÉ DO SUL - SP Y REGIÓN.}

\section{RESUMEN}

Este trabajo tuvo como objetivo evaluar las condiciones ambientales de algunas propiedades rurales en Santa Fe do Sul - SP y de la región, la evaluación de la forma en que los problemas ambientales son percibidos por los agricultores. Se elaboró un cuestionario, y de ella se llevaron a cabo 45 entrevistas con cuestiones que detectaron la existencia de la degradación ambiental y la necesidad de una mayor inversión en la educación ambiental en las zonas rurales a la ciudad de Santa Fe y la región Sur. Con el fin de evaluar las condiciones que se encuentran en las propiedades del municipio, se formuló un cuestionario con unas 26 preguntas que contiene alternativas con diferentes respuestas, centrándose en los principales problemas que causan la degradación del medio ambiente en la región en estudio. Se abordaron en las cuestiones ambientales cuestionario preocupación desde el punto de vista de la agricultura, entre los cuales son los problemas de la contaminación de cursos de agua, la existencia de bosque de ribera, sitios de lanzamiento de alcantarillado, más allá de la identificación de las fuentes de agua existentes en las propiedades. El trabajo encontró problemas en los temas abordados, tales como la falta o ausencia de bosques de ribera en las fuentes de água de las propiedades analizadas, por lo que es necesaria la aplicación de programas de educación ambiental con el fin de capacitar a más personas conscientes, generando mejoras para sí mismos y en el que viven.

PALABRAS CLAVE: Educación Ambiental. Medio Ambiente. Sostenibilidad.

\section{INTRODUÇÃO}


A sustentabilidade é um problema multidimensional. A Unesco (1995) define desenvolvimento sustentável como aquele que permite responder às necessidades presentes sem comprometer a capacidade das futuras gerações em responder às suas próprias necessidades. A amplitude da definição requer algumas qualificações. Desenvolvimento sustentável significa ir mais além da manutenção e da ampliação do capital econômico (máquinas, matérias-primas, finanças). Significa levar em conta também o capital humano: os conhecimentos técnicos e gerenciais e sua disseminação através da educação. Mas significa também levar em conta o capital natural. Por conseguinte, desenvolvimento sustentável implica em pensar no uso, obsolescência, depreciação dos três tipos de capital. No caso do capital natural, implica em perguntar como evitar a poluição da água, da terra e do ar em que vivemos e dos quais depende nosso trabalho, como evitar a exaustão dos recursos renováveis que são essenciais à produção, e tratar os recursos não renováveis (HAUWERMEINENN, 1998).

As ações antrópicas sobre ambientes naturais vêm provocando grandes alterações nos ecossistemas, sem considerar uma sustentabilidade a curto, médio e longo prazo. $\mathrm{O}$ resultado disto é uma crescente degradação ambiental, piorando a qualidade de vida e o bem-estar das populações, sendo que a cada ano são explorados os recursos naturais, desordenadamente, comprometendo a capacidade das futuras gerações de satisfazer as suas necessidades (BRITO e CÂMARA, 1998).

Segundo o IBGE (2007), cerca de 18,71\% da população brasileira vive na área rural, correspondendo a 31.845.211 habitantes que, em sua quase totalidade, lançam os esgotos diretamente nos rios, lagos ou mesmo no solo localizado nas proximidades das moradias. Este comportamento acaba piorando a contaminação dos corpos hídricos superficiais e subterrâneos, gerando sérios problemas à saúde pública e ao próprio ambiente em que vivem.

A educação ambiental é um processo permanente e participativo de explicitação de valores, instrução sobre problemas específicos relacionados com o gerenciamento do meio ambiente, formação de conceitos e aquisição de competências que motivem o comportamento de defesa, preservação e melhoria do ambiente. Em outras palavras, a educação ambiental deve levar o homem a viver em harmonia com a natureza, passando pela participação de todos os cidadãos na solução dos problemas ambientais (VERGARA FILHO, 1998). 
Desde o ano de 2000 está em desenvolvimento na UNESP, Campus de llha Solteira, um projeto de diagnóstico sócio-ambiental em propriedades agrícolas (pequenas, médias e grandes) no Estado de São Paulo, de modo a coletar dados sobre as diversas realidades do meio rural do estado. Diversos trabalhos foram realizados no contexto de tal projeto, com a finalidade de avaliar as condições ambientais das propriedades rurais e a percepção ambiental de agricultores, entre os quais podem ser citados o de Arruda et al. (2001), no Assentamento Timboré em Castilho-SP, o de Poleto et al. (2004), na microbacia hidrográfica do córrego do Ipê em llha Solteira-SP, o de Martins et al. (2005) no Assentamento Cinturão Verde de Ilha Solteira, o de Américo et al. (2012) em Dobrada, SP e o de Carvalho et al. (2012) em Santa Rita do Passa Quatro-SP.

A metodologia utilizada baseia-se em Machado (1982), Colodro et. al. (1991) e Martins et al. (2005). Espera-se que os dados obtidos possam fornecer importantes subsídios para a elaboração de programas de educação ambiental, com o intuito de conscientizar os proprietários, capacitando-os para sanar os possíveis problemas, gerando assim um melhor desenvolvimento do local.

\section{OBJETIVO GERAL}

O objetivo do presente trabalho foi realizar avaliações junto a diversos produtores rurais no município de Santa Fé do Sul, estado de São Paulo e região, com base em questões de natureza ambiental, a fim de identificar possíveis problemas nas propriedades, além de avaliar a percepção ambiental destes produtores, e como estes problemas são tratados em suas propriedades.

\section{METODOLOGIA}

\subsection{Caracterização da Área de Estudo}

Santa Fé do Sul tem população de 30.872 habitantes (IBGE, 2010) e área de $208,9 \mathrm{~km}^{2}$, pertence à Microrregião de Jales. Localiza-se a uma latitude de $20^{\circ} 12^{\prime} 40^{\prime \prime}$ sul e a uma longitude de $50^{\circ} 55^{\prime} 33^{\prime \prime}$ oeste, estando a uma altitude de 370 metros. O município localiza-se no extremo noroeste paulista, a $626 \mathrm{~km}$ da capital paulista. 
O clima de Santa Fé do Sul é o tropical Aw, segundo a classificação de Köeppen (1948), com temperatura média anual de $24^{\circ} \mathrm{C}$, tendo mínima média de $17^{\circ} \mathrm{C}$ e máxima média de $31^{\circ} \mathrm{C}$. Possui um verão marcado por temperaturas máximas sempre superiores a 33 graus, com extremos de $40{ }^{\circ} \mathrm{C}$ e mínimas raramente inferiores a $20{ }^{\circ} \mathrm{C}$, além de muita precipitação de chuva. A precipitação média anual é de $1.265 \mathrm{~mm}$. Os invernos são secos, com temperaturas mínimas em torno de 13 graus, raramente inferiores a 7 graus, e máximas em torno de 28 graus, raramente inferiores a 20 graus, sendo que a umidade relativa do ar chega a marcar valores inferiores a 15\%. (CEPAGRI, 2014).

A chamada região dos Grandes Lagos que é formada pelas usinas de llha Solteira, Jupiá e Água Vermelha, constituída pelos rios Paraná, Paranaíba, Grande, São José e Tietê, permite excelente localização à Santa Fé do Sul fazendo com que ela seja um portal para o MERCOSUL. O acesso a importantes rodovias como a Euclides da Cunha (SP 330), Washington Luiz (SP 310), Anhanguera (330) e Bandeirantes (SP 348), permite que as distâncias se encurtem na ligação entre os estados de São Paulo, Mato Grosso, Mato Grosso do Sul, Goiás e Minas Gerais (PREFEITURA MUNICIPAL, 2014).

O Município possui forte atividade econômica voltada a Agropecuária e ao agroturismo. A seguir encontram-se os resultados do Censo Agropecuário de 2006 realizado pelo IBGE. 
Tabela 01. Censo Agropecuário 2006. Santa Fé do Sul - São Paulo.

\begin{tabular}{lcc}
\hline \multicolumn{1}{c}{ Itens } & $\begin{array}{c}\text { Número de } \\
\text { estabelecimentos }\end{array}$ & Unidades \\
\hline Estab. Agropecuários & 469 & 10.993 hectares \\
Lavouras permanentes & 160 & 827 hectares \\
Lavouras temporárias & 134 & 577 hectares \\
Pastagens naturais & 60 & 5.725 hectares \\
Pastagens degradadas & 38 & 357 hectares \\
Terras degradadas & 6 & 3 hectares \\
Matas e florestas & 121 & 1.062 hectares \\
Bovinos & 413 & 27.054 cabeças \\
Equinos & 269 & 737 cabeças \\
Asininos & 3 & 3 cabeças \\
Muares & 161 & 24 cabeças \\
Caprinos & 265 & 64 cabeças \\
Ovinos & 4 & 1.171 cabeças \\
Suínos & 58 & 2.909 cabeças \\
Aves & 179 & 171 mil dúzias \\
Gado de leite & 19.000 cabeças \\
\hline Ovos & 1052 litros \\
\hline
\end{tabular}

\subsection{Amostragens e Coleta de Dados}

Para realizar a avaliação das condições encontradas nas propriedades do município de Santa Fé do Sul no estado de São Paulo e região, foi formulado um 
questionário, com cerca de 26 questões, contendo quadros com alternativas diversas de respostas, enfocando os principais problemas causadores de degradação ambiental atualmente na região em estudo. Foram abordadas no questionário questões ambientais preocupantes do ponto de vista agropecuário, entre as quais estão os problemas de contaminação de cursos d'água, existência de matas ciliares, locais de lançamento de esgoto, além da identificação das fontes de água existentes nas propriedades, enfim, a visão que o agricultor tem em relação a importância da preservação ambiental e disponibilidade futura dos recursos naturais. As propriedades rurais analisadas foram escolhidas aleatoriamente e os dados obtidos possibilitam a formação de uma visão geral dos locais estudados, servindo de subsídio para a implantação caso necessário de programas de educação ambiental, gerando melhorias para o ambiente $\mathrm{e}$ consequentemente para a vida humana.

\section{RESULTADOS E DISCUSSÃO}

\subsection{Fontes de água}

As fontes de água existentes nas propriedades são variadas, como pode ser observado na Figura 01, mas o destaque é dado aos poços, os quais estão presentes em 93,33\% das mesmas, seguido de córregos que ocorrem em 51,11\% das propriedades, enquanto que represas, açudes e lagos aparecem em $35,56 \%$ do total avaliado, apenas $11,11 \%$ das propriedades possuem nascentes, e somente $2,22 \%$ são cortadas por rios. Tais dados se contrapõem aos apresentados por Almeida (2008), em que as fontes de água das propriedades visitadas são em sua maioria provenientes de represas, lagos ou açudes, representando $27 \%$, seguidas por córregos e poços, com $24 \%$ cada, nascentes com $20 \%$ e $5 \%$ que apresentam sua área cortada por algum rio. Martins (2005) demonstra também no seu trabalho realizado no município de llha Solteira - SP, dados que diferem dos apresentados no presente trabalho, uma vez que as fontes de água apresentam as seguintes características: rios em $10 \%$, córregos em $60 \%$, nascentes em $50 \%$, represas em $60 \%$, poços semi-artesianos e cacimbas em $100 \%$ das propriedades avaliadas.

Todas as propriedades avaliadas declararam que a água proveniente das diversas fontes existentes não recebe nenhum tipo de tratamento, fato esse que pode ser 
prejudicial a saúde das pessoas residentes do local, pois sem nenhum tratamento a água pode vir a ser contaminada e ao ser consumida pelas pessoas, poderá ocasionar doenças.

Figura 01. Fontes de água existentes nas propriedades. Santa Fé do Sul - SP e região, 2014.

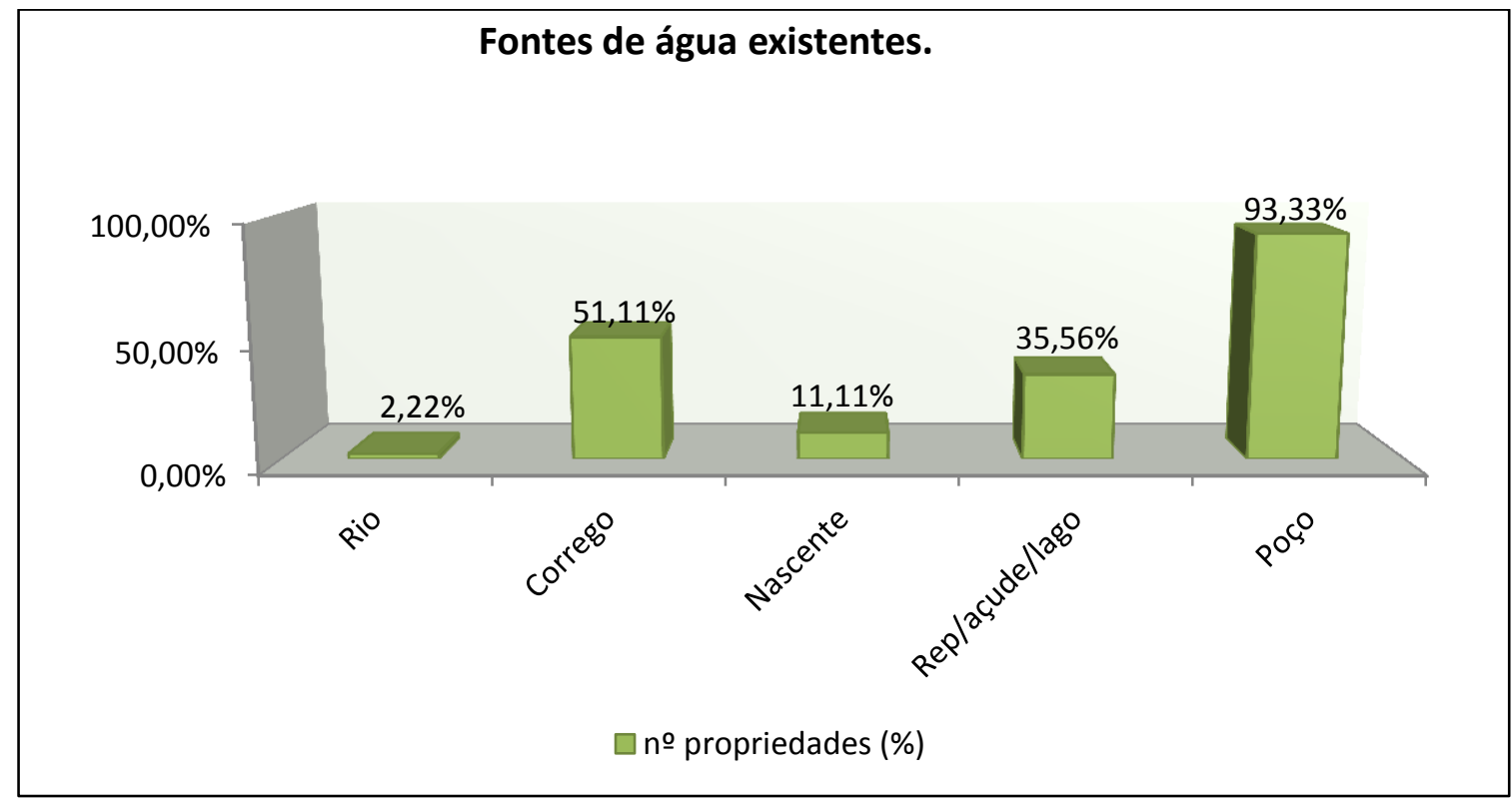

Fonte: Dados da pesquisa, 2014.

\subsection{Lançamento de esgoto nas propriedades}

Em relação ao lançamento de esgoto observa-se na Figura 02 , que $86,00 \%$ das propriedades analisadas lançam seu esgoto em fossas negras, e o restante $(14,00 \%)$ faz o uso da fossa séptica para lançamento do esgoto produzido no local. Tais dados se contrapõem aos obtidos por Prudente Junior (2013) em estudo realizado na região de Bauru-SP, onde em $70 \%$ das propriedades o esgoto é lançado em fossas sépticas, em $16,67 \%$ o esgoto é despejado em buracos, $3,33 \%$ dos estabelecimentos fazem o despejo na mata ciliar, e outros 3,33\% representam propriedades sem qualquer sistema de esgoto. Por fim, outros $3,33 \%$ despejam esgoto através de redes de tratamento da prefeitura existentes no local. 
O elevado uso de fossas negras pode ser um fator que deve observado com certa cautela, pois tais fossas não são revestidas internamente, além de não possuírem estágios adicionais, assim como os existentes nas fossas sépticas, por onde o esgoto passa, diminuindo seu potencial de infiltração no solo e consequentemente reduzindo o risco de contaminação dos lençóis freáticos, perda na qualidade da água, prejuízo ao ambiente e ao ser humano.

Figura 02. Tipo de fossa existente nas propriedades analisadas. Santa Fé do Sul - SP e região, 2014.

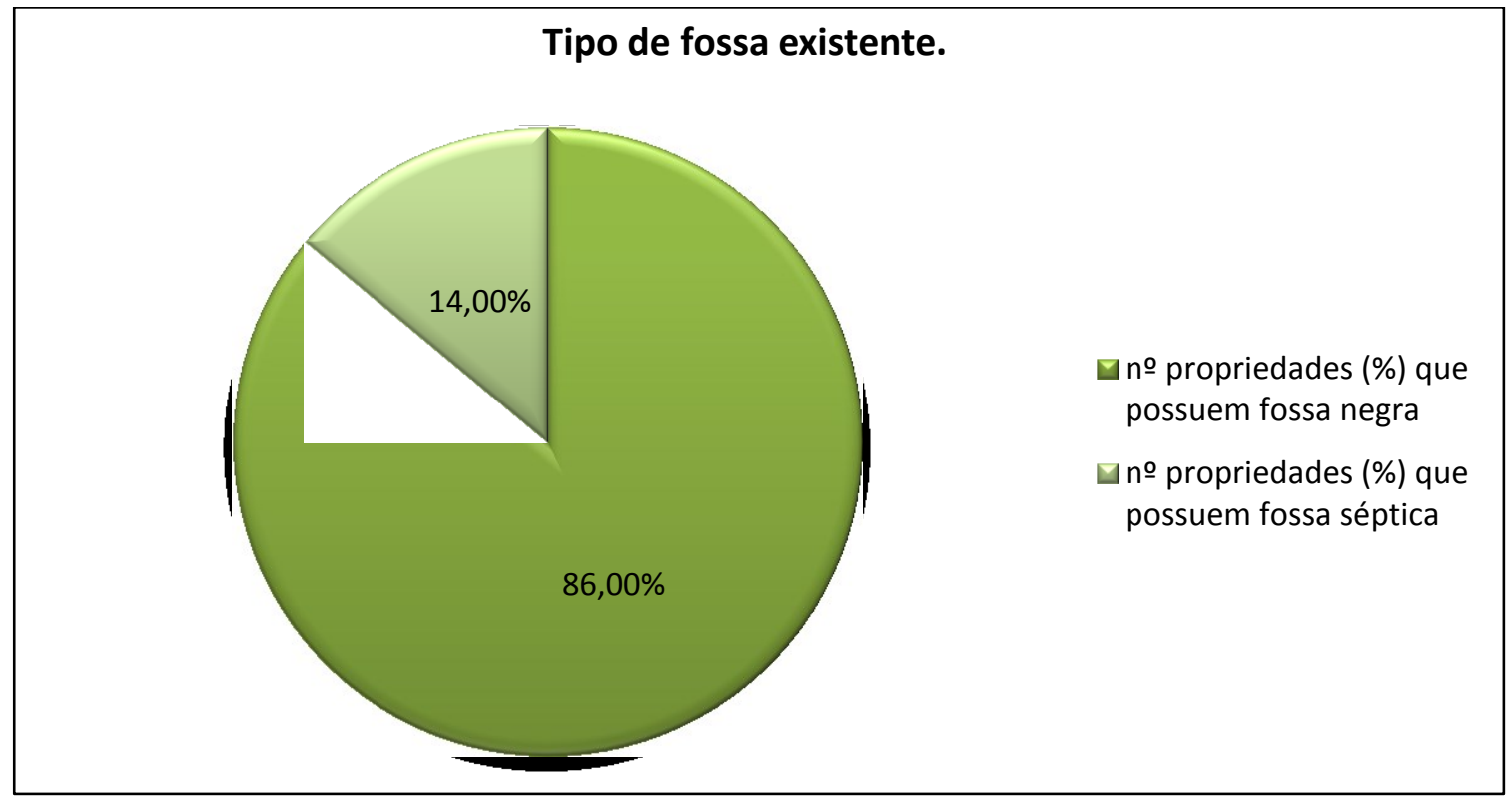

Fonte: Dados da pesquisa, 2014.

\subsection{Mata ciliar}

Segundo Martins (2005), a preservação e a recuperação das matas ciliares, aliadas as práticas de conservação e ao manejo do solo, garantem a proteção de um dos principais recursos naturais: a água. A degradação ambiental provocada por práticas agrícolas inadequadas é conceituada como agente modificador do meio ambiente através dos processos causadores de danos que alteram as características originais além do limite de sua recuperação natural, que envolvem os solos, a vegetação, os cursos de água, enfim, exigindo dessa maneira a intervenção de pessoas para sua recuperação. 
As novas técnicas utilizadas objetivando maiores produções, como a utilização de agrotóxicos e a constante exploração de uso de solos, causam graves problemas de conservação dos solos e dos recursos hídricos. Devido ao desmatamento indiscriminado e a ocupação de áreas impróprias ao cultivo, trouxeram desequilíbrios ambientais, como erosão, assoreamento e poluição dos cursos de água. Nossa dependência pelos recursos naturais se intensifica, e se faz dia a dia, maior a necessidade de conscientização das comunidades rurais acerca dos problemas em sua utilização e necessidade de proteção e conservação.

Observa-se na Figura 03, que boa parte das propriedades não possui mata ciliar em suas fontes de água, $100 \%$ delas não possuem mata ciliar nos rios que as cortam, as análises mostraram também que em $90 \%$ das propriedades, as represas existentes não possuem mata ciliar, contra $10 \%$ que as possui. Dos córregos existentes nas propriedades, $70 \%$ tem mata ciliar em suas margens, enquanto que $30 \%$ dos mesmos são carentes deste tipo de mata. No caso das nascentes, apenas $60 \%$ das propriedades apresentaram esta fonte de água contendo mata ciliar, no restante $(40 \%)$ ocorre ausência desse tipo de vegetação. Por fim $67 \%$ dos estabelecimentos analisados apresentaram açudes contendo mata ciliar, e os outros 33\% não tem este tipo de mata. Martins (2005) em trabalho realizado no município de ilha Solteira-SP encontrou resultados diferentes dos observados no presente trabalho, uma vez que em áreas remanescentes de vegetação ripária encontrada nas propriedades, a presença de matas ciliares ocorre em apenas $13 \%$ das propriedades agrícolas estudadas enquanto que em $87 \%$ delas esta vegetação é inexistente.

Tendo em vista tais informações é aconselhável que seja feito um trabalho de conscientização junto aos proprietários, visando informar-lhes dos prejuízos a curto, médio e longo prazo causado pela ausência desse tipo de vegetação, uma vez que as fontes de água podem vir a sofrer assoreamento, culminando na secagem completa. 
Figura 03. Condição da mata ciliar existente nas propriedades analisadas. Santa Fé do Sul - SP e região, 2014.

\begin{tabular}{|c|c|c|c|c|c|c|c|c|}
\hline \multicolumn{10}{|c|}{ Condição da mata ciliar nas propriedades analisadas. } \\
\hline $100 \%$ \\
\hline $50 \%$
\end{tabular}

Fonte: Dados da pesquisa, 2014.

\section{CONCLUSÃO}

Com os resultados obtidos no presente trabalho foi possível concluir que as propriedades analisadas possuem problemas em relação ao não tratamento da água usada para consumo e demais atividades. Essa ação pode trazer doenças e outros males, sendo então necessária a conscientização dos proprietários a respeito da importância do tratamento da água. Foi observado também a baixa existência de mata ciliar nas fontes de água, tal ausência pode trazer problemas a curto médio e longo prazo, culminando no esgotamento e consequente perda da fonte d'água. Outro problema encontrado diz respeito ao lançamento de esgoto em fossa negra/comum, que consiste em um sistema pouco seguro, uma vez que não possui capacidade de diminuição do potencial de contaminação do solo e lençóis freáticos, pois não possui paredes revestidas e não apresentam demais estágios de filtragem como os encontrados em fossas sépticas, dessa forma o emprego de tais fossas negras/comuns tornam-se perigosas ao ambiente em que estão sendo usadas. 
Sendo assim, com o intuito de sanar os problemas e gerar um melhor desenvolvimento do local, faz-se necessário a implantação de um programa de educação ambiental nessa região, a fim de formar pessoas mais conscientes e capazes de realizar ações preventivas, além de fazer a identificação e fiscalização dos agentes causadores de desequilíbrio ambiental.

\section{REFERÊNCIAS}

AMÉRICO, J.H.P.; CARVALHO, S.L.; FREITAS LIMA, E.A.C.;ARAÚJO, C.A.M. Condições ambientais de propriedades agrícolas e percepção ambiental de produtores rurais da região de Dobrada - São Paulo, Brasil. Holos Environment, v.12, n 2, p. 241-249, 2012.

ALMEIDA, F. Avaliação das condições sócio - econômicas - ambientais de algumas propriedades agrícolas no município de Santa Rita do Passa Quatro. São Paulo. Monografia apresentada ao Curso de Agronomia da Faculdade de Engenharia - Campus de Ilha Solteira - São Paulo. 2008.

ARRUDA, S.A. CARVALHO, S.L.; FREITAS LIMA, E.A.C.; ARAÚJO, C.A.M. Percepção ambiental de produtores rurais e das condições ambientais de seus lotes agrícolas no Assentamento Timboré em Castilho-SP. In: III Encontro Sobre Educação Ambiental na Agricultura. Campinas-SP, 2001.

BRITO, F.A. E CÂMARA, B.D. Democratização e Gestão Ambiental: em busca do desenvolvimento sustentável, 2.ed. Petrópolis, RJ, Vozes, 1998,p.36-42.

CARVALHO, S.L.; ALMEIDA, F., FREITAS LIMA, E.A.C. Avaliação das Condições Sócio-EconômicoAmbientais de Algumas Propriedades Agrícolas no Município de Santa Rita do Passa Quatro SP. Fórum Ambiental da Alta Paulista, v. 8, p.348-359, 2012.

CEPAGRI. Clima do Município de Santa Fé do Sul. Disponível em: http://www.cpa.unicamp.br/outrasinformacoes/clima_muni_524.html. Acesso em 24 de julho de 2014.

COLODRO, G., MORAES, M.L., CARVALHO, S. L. Conservação da natureza e Educação em Algumas Cidades do Estado de São Paulo. In: Seminário Regional de Ecologia, 6, 1989, São Carlos, Anais... UFSCAR,1991,529-546.

IBGE - Instituto Brasileiro de Geografia e Estadística. Pesquisa Nacional de Saneamento Básico. Disponível em: http://www.ibge.gov.br. 11 Abr. 2007. Acesso em 25 de julho de 2014

IBGE, 2010. Cidades. Disponível em: http://cidades.ibge.gov.br/xtras/perfil.php?codmun=354660. Acesso em 25 de julho de 2014.

HAUWERMEINEN, S.V. Manual de Economia Ecológica. Santiago, Chile, 1998

MACHADO, A.B.M. Conservação da Natureza e Educação. Silvicultura em São Paulo, v.16, n.1, p. 109118, 1982.

MARTINS, M.; CARVALHO, S.L.; FREITAS LIMA, E.A.C.; ARAUJO, C.A.M.; SANTANA,A.L. Avaliação das condições sócio-econômicas de algumas propriedades agrícolas no município de llha Solteira/SP. In: Congresso Brasileiro de Administração Rural (ABAR), 5. 14-19 de agosto de 2005, Campinas. Anais...CDROM. $16 p$.

POLETO, C.; CARVALHO, S.L; FREITAS LIMA, E.C. Problemas de degradação ambiental em uma microbacia hidrográfica situada no município de llha Solteira - SP, Brasil e sua percepção pelos proprietários rurais. Holos Environment, v. 4, n.1, p. 68-80, 2004. 
PREFEITURA MUNICIPAL. Santa Fe do Sul. Disponível em: <http://www.santafedosul.sp.gov.br/>. Acesso em 25 de junho 2014

PRUDENTE JUNIOR, A.C.; CARVALHO, S.L.; FREITAS LIMA, E.A.C. Percepção ambiental de produtores rurais e condições ambientais de algumas propriedades agrícolas da região de Bauru - SP (dados parciais). IX Fórum Ambiental da Alta Paulista, v. 9, n. 6, 2013, p. 105-116.

VERGARA FILHO, O., VAlE, N., DUARTE, M., MACHADO, W.T.V., NUNES, A.E., SANTIAGO, A.N. A Educação Ambiental como Subsídio ao Projeto de ocupação das Encostas da Cidade do Rio de Janeiro. In: Seminário Regional de Ecologia, 8, 1998, São Carlos, Anais...UFSCAR, 1998, 449-458. 